\title{
Two unlinked loci controlling the sex of blue tilapia (Oreochromis aureus)
}

\author{
B-Y Lee ${ }^{1}$, G Hulata ${ }^{2}$ and TD Kocher ${ }^{1}$ \\ ${ }^{1}$ Hubbard Center for Genome Studies, Suite 400, Environmental Technology Building, 35 Colovos Road, University of New Hampshire, \\ Durham, NH 03824, USA; ${ }^{2}$ Department of Aquaculture, Institute of Animal Science, Agricultural Research Organization, Volcani \\ Center, PO Box 6, Bet Dagan 50250, Israel
}

\begin{abstract}
Sex determination in the blue tilapia (Oreochromis aureus) is thought to be a WZ-ZZ (female heterogametic) system controlled by a major gene. We searched for DNA markers linked to this major gene using the technique of bulked segregant analysis. We identified 11 microsatellite markers on linkage group 3 which were linked to phenotypic sex. The putative W chromosome haplotype correctly predicts the sex of $97 \%$ of male and $85 \%$ of female individuals. Our results suggest the $\mathrm{W}$ locus lies within a few centimorgans of markers GM354, UNH168, GM271 and UNH131. Markers on
\end{abstract}

LG1 also showed a strong association with sex, and indicate the segregation of a male-determining allele in this region. Analysis of epistatic interactions among the loci suggests the action of a dominant male repressor (the W haplotype on LG 3 ) and a dominant male determiner (the $Y$ haplotype on LG1). These markers have immediate utility for studying the strength of different sex chromosome alleles, and for identifying broodstock carrying copies of the $\mathrm{W}$ haplotype. Heredity (2004) 92, 543-549, advance online publication, 21 April 2004; doi:10.1038/sj.hdy.6800453

Keywords: blue tilapia; sex determination; microsatellite markers; evolution; teleost; epistasis

\section{Introduction}

The mechanisms of animal sex determination are diverse and highly labile (Bull, 1983). Even among species where sex is genetically (rather than environmentally) determined, different genes have been implicated as the primary regulators of sexual differentiation. For example, in evolutionary terms, the $\mathrm{Y}$ chromosome of mammals is recent, having first appeared between 170 and $300 \mathrm{MY}$ ago. Sry, the gene that initiates the male differentiation cascade in mammals, does not control the sex of monotremes, and so must have taken on a role in sex determination within the last 170 MY (Graves, 2002). A few species of mole have recently lost Sry, and accomplish sex determination by a still unknown mechanism (Just et al, 2002). Birds have a female heterogametic (WZ) system which arose from a different pair of autosomes than the XY chromosomes of mammals some $350 \mathrm{MY}$ ago (Nanda et al, 1999). Birds apparently lack Sry, and the genetic mechanism for sex determination in these species remains a mystery.

The diversity of sex-determining mechanisms has slowed the development of a unifying theory for the evolution of sex-determining pathways. It now appears that a variety of primary signals regulate one or a few ancient proximate pathways of differentiation (Zarkower, 2001). Wilkins (2002) proposed a hypothesis for the elaboration of sex-determining pathways by retro-

Correspondence: TD Kocher, Hubbard Center for Genome Studies, Suite 400, Environmental Technology Building, 35 Colovos Road, University of New Hampshire, Durham, NH 03824, USA;

E-mail:Tom.Kocher@unh.edu

Received 31 March 2003; accepted 24 February 2004; published online 21 April 2004 grade addition of upstream regulators. In his model, the downstream steps in the genetic pathway are conserved, but new regulators, especially inhibitory factors, are frequently recruited at upstream steps. Wilkins' model is consistent with what is known about the structure of sexdetermining pathways in insects, nematodes and mammals (Gilbert, 1997).

Teleosts display a wonderful variety of mechanisms for sex determination and sex differentiation (reviewed in Devlin and Nagahama, 2002). Sex differentiation of fishes is remarkably plastic, and sex is determined by environmental factors in many species (Baroiller et al, 1999). A few species even undergo sex change in response to behavioral cues (Devlin and Nagahama, 2002).

Fishes provide interesting material for studying the evolution of sex chromosomes. Although genetic factors probably regulate sex determination in most fishes, relatively few teleosts have karyotypically distinct sex chromosomes (Arkhipchuk, 1995). In most species, the sex chromosomes are still in early stages of differentiation, and do not show distinct differences in length or gene content. Both XY and WZ gonosomal systems have evolved repeatedly in various groups of fishes (Devlin and Nagahama, 2002). Additional autosomal loci also contribute to sex determination in many species (Kosswig, 1964). In only one fish species (medaka) has the primary sex-determining gene been identified (Matsuda et al, 2002; Nanda et al, 2002). DMY is a new doublesex/ mab-3 gene most closely related to DMRT1 (Kondo et al, 2003). It is expressed in developing male (but not female) gonads and appears to be necessary for differentiation of testes. Surprisingly, no sex-linked markers have been identified in the well-studied zebrafish, or the pufferfish (Li et al, 2002). 
Tilapia reach sexual maturity in just a few months and often begin reproducing in grow-out ponds before they reach a marketable size, reducing the yield and value at harvest. Therefore, commercial production of tilapia often relies on monosex culture of males. Beginning with the work of Hickling (1960), a variety of methods have been used to produce unisex fingerlings, including interspecific hybridization (Wohlfarth and Hulata, 1983), hormone treatment (Phelps and Popma, 2000) and YY supermales (Mair et al, 1997). These methods are not entirely reliable, in part because of their technical complexity (eg Wohlfarth, 1994), but also because the sex of tilapia is affected by environmental factors such as temperature (Baroiller et al, 1995; Desprez and Mélard, 1998; Abucay et al, 1999), and may also be influenced by additional genes (Mair et al, 1991; Hussain et al, 1994; Sarder et al, 1999).

Oreochromis aureus has been described as having a predominantly female-heterogametic (WZ) system of sex determination (Mair et al, 1991). Crosses of hormonally sex-reversed $\mathrm{ZZ}$ phenotypic females with normal $\mathrm{ZZ}$ males usually produce $100 \%$ male offspring, but slight deviations have been observed (Hopkins et al, 1979; Mair et al, 1987; Lahav, 1993; Rosenstein and Hulata, 1994). Gynogenesis has also been used to study sex determination. If $O$. aureus females are $W Z$, then a ratio of one female (WW): one male (ZZ) is expected in their gynogenetic offspring. Yet, these fish produced a predominance of females in the $F_{1}$ generation. Penman et al (1987) explained this by hypothesizing a recombination of sex-determining genes in prophase of the first meiotic division. Thus a single crossover would yield an all-female (WZ) population, while double crossovers would produce equal numbers of males and females. The large number of crossovers suggested a distance of about $25 \mathrm{cM}$ between the centromere and the sex-determining genes (Penman et al, 1987). This hypothesis was further investigated by Avtalion and Don (1990), who found that WZ females can produce, in all descending gynogenetic generations, offspring expressing a male genotype (ZZ) and two different female genotypes (WW and WZ), thus leading to a greater fraction of female progeny. Further studies by Mair et al (1991) confirmed female heterogamety, but also suggested the involvement of an autosomal recessive modifier. This study, as well as those of Hopkins (1979) and Mélard (1995), demonstrated male homogamety for this species. A monofactorial sex determination system with two sex chromosomes (WZ) in O. aureus was also supported by results from the analysis of progeny sex ratios from pseudofemales (Desprez et al, 2003), who showed that it is possible to obtain high proportions of male progeny from successive generations of pseudofemales by hormonal sex reversal and progeny testing.

The sex chromosomes of tilapia are relatively undifferentiated. There are no gross morphological differences in any chromosome pair that would identify the sex chromosomes (Kornfield, 1984; Majumdar and McAndrew, 1986). Campos-Ramos et al (2001) visualized the synaptonemal complex of $O$. aureus and observed incompletely paired segments in the longest bivalent and a smaller bivalent, which they suggested could be the sex-determining regions. Association between loci with deleterious alleles and distorted sex ratios has recently been reported in an inbred line of $O$. aureus
(Shirak et al, 2002), but to this point, no DNA sequence markers for the major sex-determining locus in O. aureus have been described. We have recently constructed a linkage map for tilapia which contains more than 550 microsatellite markers (Lee et al, in prep.). Here we use markers selected from this map to rapidly scan the genome for sex-linked markers in bulked segregants. We then study genotypes of individual fish to localize the sex-determining regions and study epistatic interactions among loci.

\section{Materials and methods}

\section{Fish source and DNA extraction}

A single family of tilapia (O. aureus), produced at the Agricultural Research Organization, Israel, was used for this study. The history of cultured stocks of tilapia is typically uncertain, but this stock is to the best of our knowledge free of introgression from other species. Crossing males of this stock with $O$. niloticus females results in $100 \%$ male offspring, which further supports it purity. Offspring were sexed at the age of $\sim 4$ months (at a mean size of $\sim 25 \mathrm{~g}$ ) by macroscopic inspection of gonads, or by microscopic examination using the technique of Guerrero and Shelton (1974). Fin-clips from each fish were then dried and sent to the University of New Hampshire for genotyping. DNA was extracted from the fin-clips using the standard phenol/chloroform method (Kocher et al, 1989).

\section{Marker selection}

We selected 119 microsatellite markers, at intervals of approximately $20 \mathrm{cM}$, based on a linkage map produced from an $F_{2}$ population from the interspecies cross of $O$. aureus with $O$. niloticus (Lee et al in prep; see map at http:/ / hcgs.unh.edu/comp). Those markers consisted of 92 UNH markers, 24 GM markers and three genes (CLCN5, RAS-GRF2, UV-Opsin), all of which are deposited in GenBank. Linkage group numbers in this manuscript are harmonized, to the extent possible, with the previous linkage map of tilapia (Kocher et al, 1998). Note in particular that the markers on the O. niloticus sex chromosome described by Lee et al (2003) are to be found on LG1 of the new map.

\section{Bulked segregant analysis}

To accelerate the identification of sex-linked markers, we used the technique of bulked segregant analysis (Michelmore et al, 1991). We made separate pools of 24 male and 24 female DNAs. Before pooling, the concentration of the DNAs was quantified using a DyNA Quant2000 spectrofluorometer (Amersham Pharmacia Biotech, Piscataway, NJ, USA) and each DNA was diluted to a final concentration of $\sim 10 \mathrm{ng} / \mu \mathrm{l}$. This allowed us to equalize the contribution of each individual to the pool. PCR was performed in a total volume of $20 \mu \mathrm{l}$ for $2 \mathrm{~min}$ at $94^{\circ} \mathrm{C}$ followed by 28 cycles of $30 \mathrm{~s}$ at $94^{\circ} \mathrm{C}, 30 \mathrm{~s}$ at $55-60^{\circ} \mathrm{C}, 60 \mathrm{~s}$ at $72^{\circ} \mathrm{C}$, with a final elongation step of $5 \mathrm{~min}$ at $72^{\circ} \mathrm{C}$. One primer in each pair was labeled with a HEX, TET or FAM fluorescent dye (Operon Technologies, Alameda, CA, USA). PCR products were separated on an ABI377 DNA sequencer and fragment sizes were analyzed using ABI GeneScan 3.1.2 software (Applied Biosystems, Foster City, CA, USA). 
Genotyping and statistics

For those markers that showed a qualitative difference in allelic composition in the pooled DNA, we repeated the genotyping on individual DNA samples from 48 females and 45 males using the same PCR conditions described above. We genotyped these individuals for all available markers on LG1 (nine markers) and LG3 (11 markers; Table 1). Goodness-of-fit (G-tests) were used to assess whether there were significant differences in genotypic distributions between males and females (Sokal and Rohlf, 1981). Significance thresholds were Bonferroni corrected for the number of chromosome arms (27), as reported by Majumdar and McAndrew (1986).

Mapping of sex-linked markers

Linkage maps for the sex-linked chromosomes were constructed from the segregation in this family. Linkage

Table 1 Genotypic proportions for sex-linked markers in male and female O. aureus. Asterisks indicate the Bonferroni-corrected $P$-values for each test

\begin{tabular}{|c|c|c|c|c|c|c|c|c|c|}
\hline & & G3 & & & & & G1 & & \\
\hline Marker & Genotypes & Female & Male & G-test & Marker & Genotypes & Female & Male & G-test \\
\hline GM139 & $193 / 193$ & 6 & 1 & $35.58^{* * *}$ & GM041 & $232 / 232$ & 8 & 18 & 8.03 \\
\hline & $193 / 223$ & 14 & 16 & & & $232 / 238$ & 26 & 20 & \\
\hline & $193 / 218$ & 13 & 0 & & & $238 / 238$ & 13 & 5 & \\
\hline & $218 / 223$ & 3 & 21 & & & & & & \\
\hline & & & & & UNH213 & $170 / 170$ & 18 & 32 & $10.6^{*}$ \\
\hline GM354 & $129 / 137$ & 4 & 24 & $78.69^{* * *}$ & & $170 / 226$ & 30 & 13 & \\
\hline & $129 / 169$ & 4 & 19 & & & & & & \\
\hline & $137 / 137$ & 23 & 0 & & UNH148 & $161 / 148$ & 28 & 12 & 9.2 \\
\hline & $137 / 169$ & 17 & 0 & & & $161 / 157$ & 19 & 31 & \\
\hline GM271 & $121 / 125$ & 5 & 28 & $54.4^{* * *}$ & GM201 & $165 / 179$ & 13 & 10 & $20.89^{* *}$ \\
\hline & $125 / 125$ & 34 & 1 & & & $165 / 204$ & 16 & 1 & \\
\hline & & & & & & $179 / 190$ & 9 & 19 & \\
\hline UNH168 & $158 / 170$ & 3 & 22 & $84.11^{* * *}$ & & $190 / 204$ & 9 & 15 & \\
\hline & $158 / 174$ & 4 & 23 & & & & & & \\
\hline & $170 / 174$ & 24 & 0 & & UNH104 & $137 / 185$ & 16 & 1 & $20.94^{* *}$ \\
\hline & $170 / 170$ & 16 & 0 & & & $137 / 189$ & 14 & 16 & \\
\hline & & & & & & $181 / 185$ & 11 & 11 & \\
\hline UNH131 & $193 / 193$ & 5 & 35 & $75.69^{* * *}$ & & $181 / 189$ & 6 & 17 & \\
\hline & 187/193 & 38 & 0 & & JNH995 & $174 / 223$ & 16 & 2 & 1454 \\
\hline UNH115 & $168 / 182$ & 8 & 24 & $66.04^{* * *}$ & & $174 / 228$ & 10 & 14 & \\
\hline & $168 / 184$ & 21 & 0 & & & $219 / 223$ & 9 & 7 & \\
\hline & $170 / 182$ & 2 & 18 & & & $219 / 228$ & 9 & 16 & \\
\hline & $170 / 184$ & 16 & 1 & & & & & & \\
\hline & & & & & UNH868 & $220 / 216$ & 20 & 33 & 9.28 \\
\hline CLC5 & $191 / 256$ & 1 & 18 & $57.89 * * *$ & & $220 / 224$ & 26 & 11 & \\
\hline & $191 / 281$ & 16 & 0 & & & & & & \\
\hline & 191/191 & 13 & 24 & & UNH846 & $179 / 203$ & 10 & 8 & 11.55 \\
\hline & $256 / 281$ & 12 & 0 & & & $179 / 213$ & 15 & 3 & \\
\hline & & & & & & $203 / 213$ & 8 & 15 & \\
\hline GM024 & $117 / 142$ & 16 & 1 & $44.65^{* * *}$ & & $213 / 213$ & 13 & 18 & \\
\hline & $117 / 154$ & 13 & 1 & & & & & & \\
\hline & $125 / 142$ & 9 & 22 & & GM258 & $130 / 130$ & 15 & 2 & 11.83 \\
\hline & $124 / 154$ & 2 & 16 & & & $130 / 174$ & 14 & 17 & \\
\hline & & & & & & $174 / 174$ & 19 & 25 & \\
\hline UNH971 & $214 / 230$ & 18 & 1 & $44.4^{* * *}$ & & & & & \\
\hline & $214 / 234$ & 15 & 2 & & & & & & \\
\hline & $216 / 230$ & 10 & 23 & & & & & & \\
\hline & $216 / 234$ & 3 & 17 & & & & & & \\
\hline GM150 & $132 / 132$ & 32 & 14 & $16.6^{* *}$ & & & & & \\
\hline & $132 / 186$ & 13 & 34 & & & & & & \\
\hline GM635 & $226 / 226$ & 15 & 22 & $31.18^{* * *}$ & & & & & \\
\hline & $226 / 228$ & 18 & 0 & & & & & & \\
\hline & $228 / 228$ & 7 & 19 & & & & & & \\
\hline
\end{tabular}

${ }^{*} P<0.05 ;{ }^{* *} P<0.01 ; * * * 00.001$ 
analysis was performed by Crimap (Green et al, 1990) using the TWO-POINT command with a LOD of 3.0. Map orders were decided by the ALL routine and confirmed by FLIPS. The sex-specific and sex-averaged maps were made using the BUILD command.

\section{Results}

Identification of sex-linked markers in pooled DNA Amplification was successful for 102 of the 119 markers. Nine of these showed differential allelic segregation between male and female DNA pools. Five of these nine markers (CLC5, GM271, GM354, UNH131 and UNH971) belong to LG3. The 256 and $281 \mathrm{bp}$ alleles of CLC5 were more frequent in the female pool, while the $191 \mathrm{bp}$ allele was present in both the male and female pools. Both sexes had a $193 \mathrm{bp}$ allele at UNH131, but females also carried a $187 \mathrm{bp}$ allele. Alleles unique to the male pool were found at GM271 (121 bp) and GM354 (129bp). UNH971 had 230 and 234 bp alleles in both pools but the female pool had a unique $213 \mathrm{bp}$ allele and the male pool had a unique $215 \mathrm{bp}$ allele.

Two markers on LG1 (UNH213 and UNH868) also showed a difference between the male and female pools. UNH213 showed a $170 \mathrm{bp}$ allele in both sexes and an extra $226 \mathrm{bp}$ allele in the female pool. UNH868 showed $220 \mathrm{bp}$ in both sexes, an additional $224 \mathrm{bp}$ in the female pool and a $216 \mathrm{bp}$ allele in the male pool.

The other two markers (GM210 and UNH129) appear to be false positives. We tested another marker (UNH424) located only $5 \mathrm{cM}$ from GM210, but it showed no difference between the male and female pools. The extra band in the female pool for UNH129 was determined to be extraneous signal bleeding from an adjacent lane of the gel.

\section{Analysis of individual genotypes}

These preliminary results encouraged us to individually genotype animals for these and other markers on LG1 and LG3. The genotypic proportions in males and females, and the associated G-tests, are shown in Table 1. The strongest associations were with a femaledetermining haplotype on LG3. All individuals with the $187 \mathrm{bp}$ allele at UNH131 were females. Figure 1 plots the proportion of individuals whose phenotypic sex was consistent with the hypothesized female chromosome. The graph shows a broad peak around $30 \mathrm{cM}$ in females, which corresponds to markers GM354, UNH168, GM271 and UNH131. Flanking markers show a decreasing correspondence with phenotypic sex, as recombination breaks up the association with the putative female haplotype. All males are homozygous for a haplotype marked by a $193 \mathrm{bp}$ allele at UNH131.

This family is also segregating for a male-determining factor on LG1, which is epistatic to the locus on LG3. Individuals homozygous for the $193 \mathrm{bp}$ allele at UNH131 can be either male or female, depending on their genotype for the locus on LG1. All 193/193 (UNH131) individuals with an $189 \mathrm{bp}$ allele at UNH104 were males (Table 2). In all, 10 of the 193/193 (UNH131) individuals not having the $189 \mathrm{bp}$ allele at UNH104 were male, but five were phenotypic females.

Although our family sizes are small, there are some clear differences in the pattern of recombination in the

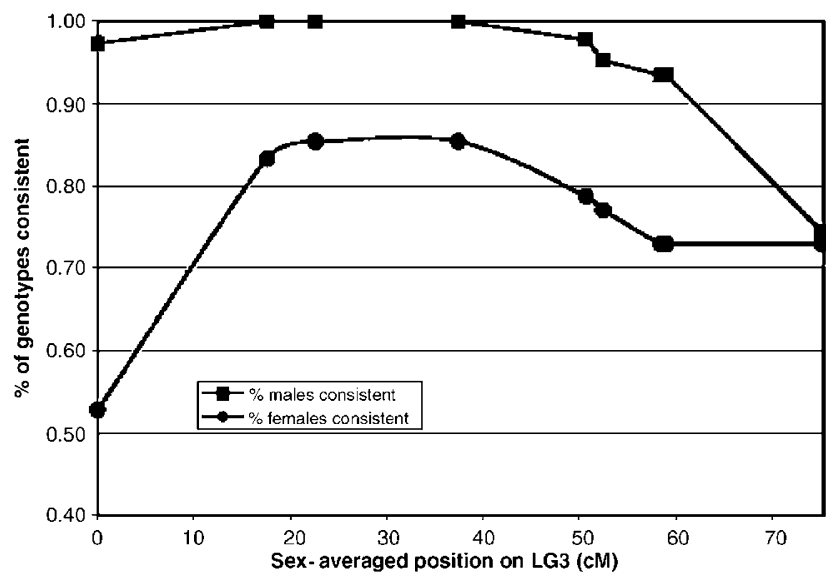

Figure 1 Proportion of individuals whose phenotypic sex is consistent with the hypothesized female determining haplotype on LG3. The map spans markers GM139 to GM150; markers UNH168 and GM271 both map to $22.6 \mathrm{cM}$. The parents were not informative for marker GM635 (88 cM).

male and female parents (Figure 2). The male map shows reduced recombination in the vicinity of the sexdetermining locus on both LG1 and LG3, and an expansion relative to the female map in distal regions. These large variations along the chromosome make it difficult to tell which sex has greater recombination on average, and we cannot yet relate the pattern to the location of centromeres.

\section{Discussion}

We detected two unlinked loci which interact to determine sex in this family of $O$. aureus. Our interpretation of the data, and our use of the WXYZ notation for sex-determining loci (or chromosomes), is as follows:

The first locus is located on LG3. Significant differences in genotypic proportions, suggestive of a $W$ haplotype, are detected for 11 microsatellite markers on this linkage group. The sex-determining locus appears to lie near markers GM354, UNH168, GM271 and UNH131. The $193 \mathrm{bp}$ allele at UNH131 is a marker for the Z allele, and the $187 \mathrm{bp}$ allele is a marker for the W. Hence, the ZZ genotype corresponds to the homozygote 193/193, while the WZ genotype is represented by the $187 / 193$ heterozygote. Essentially, $100 \%$ of the individuals with the $\mathrm{W}$ haplotype are females.

Among ZZ individuals, sex is primarily determined by the genotype of markers on LG1. This second locus is closely associated with marker UNH104. An ' $X Y^{\prime}$ ' sexdetermining locus at this position was also detected in two O. niloticus families described in Lee et al (2003). The $189 \mathrm{bp}$ allele at UNH104 is a marker for the Y chromosome and any alternative allele is a marker for the $X$ allele. Hence, the XY genotype corresponds to heterozygotes carrying the $189 \mathrm{bp}$ allele, and all other allelic combinations at UNH104 represent the XX genotype. ZZ individuals carrying a putative $\mathrm{Y}$ haplotype are $100 \%$ male.

Our results suggest that the $X Y$ and WZ systems are not allelic. This is in contrast to the assumptions of many previous theoretical treatments of the system. Most tilapia geneticists publishing in the late 1970s assumed 
that maleness in the WZ system would be determined by the action of a male-determining $Z$, rather than the absence of a dominant female determiner (W). According to a four gonosome model, $O$. niloticus would consist of $X X$ females and $X Y$ males, while $O$. aureus would consist of WZ females and $\mathrm{ZZ}$ males, where $\mathrm{Z}=\mathrm{Y}$. Hybrid crosses of presumptive $\mathrm{XX} O$. niloticus females with presumptive $\mathrm{ZZ} \mathrm{O}$. aureus males would be expected to produce all-male $(X Z)$ offspring.

In our terminology, we must consider a dilocus genotype. We do not know the allelic state for the LG3 WZ locus in O. niloticus, or the allelic state for the LG1 $X Y$ locus in $O$. aureus. So, we postulate the O. niloticus female as (??XX) and the O. aureus male as (ZZ??). The hybrids are then (Z?X?) and expected to be largely male, but may show some proportion of females depending on their genotype for additional sex-modifying loci. Pruginin et al (1975) observed anywhere from 52 to $100 \%$ males in such pair crosses. This may, however, have been

Table 2 Epistatic interactions of the sex-determining loci on LG1 and LG3 in a family of $O$. aureus

\begin{tabular}{lll}
\hline UNH131 & \multicolumn{2}{c}{ UNH104 } \\
\cline { 2 - 3 } & $A / A$ & $A / 189$ \\
\hline $187 / 193$ & 20 females & 18 females \\
& 0 males & 0 males \\
$193 / 193$ & 5 females & 0 females \\
& 10 males & 25 males \\
\hline
\end{tabular}

'A' stands for alleles other than 189 bp at locus UNH104 (eg 137, 181 or $185 \mathrm{bp}$ ). the result of using impure/contaminated stocks of one or both species. Later studies carried out in Israel have shown that $100 \%$ males can be obtained when 'good' stocks are being used (eg Lahav and Lahav, 1990; Hulata et al, 1995). These 'good' stocks have presumably been purged of any sex-modifying variation. The presence of both males and females in the putative ZZXX genotypic class of our family is consistent with the influence of additional 'autosomal' loci affecting sex ratio.

It is now commonly accepted (eg Wohlfarth and Wedekind (1991) and Trombka and Avtalion (1993)) that sex determination in tilapias is based on major (sex chromosome) genes and minor (autosomal) modifiers. The LG1 locus identified in the present work may well be the 'autosomal locus' suggested by Hammerman and Avtalion (1979), affecting sex ratios through epistatic interactions with the major WZ locus located on LG3 in $O$. aureus. This same locus, probably inherited by both $O$. aureus and $O$. niloticus from a common ancestor, could in turn be the major sex-determining gene operating in $O$. niloticus. It should be noted, however, that our notation does not fit exactly the model of Hammerman and Avtalion (1979). They based their model on an assumption that each species (both males and females) is homozygous for a different allele at the modifying autosomal locus, which becomes heterozygous in the hybrids. If our LG1 locus is that autosomal modifying locus, then it appears to have different allelic combinations in males and females of $O$. aureus.

Our results are largely consistent with the model of Mair et al (1991). They postulated a WZ sex chromosome system with an autosomal recessive allele inducing female sex. Since the homozygous ZZXX animals in our family are of mixed sex (67\% male), we suggest that

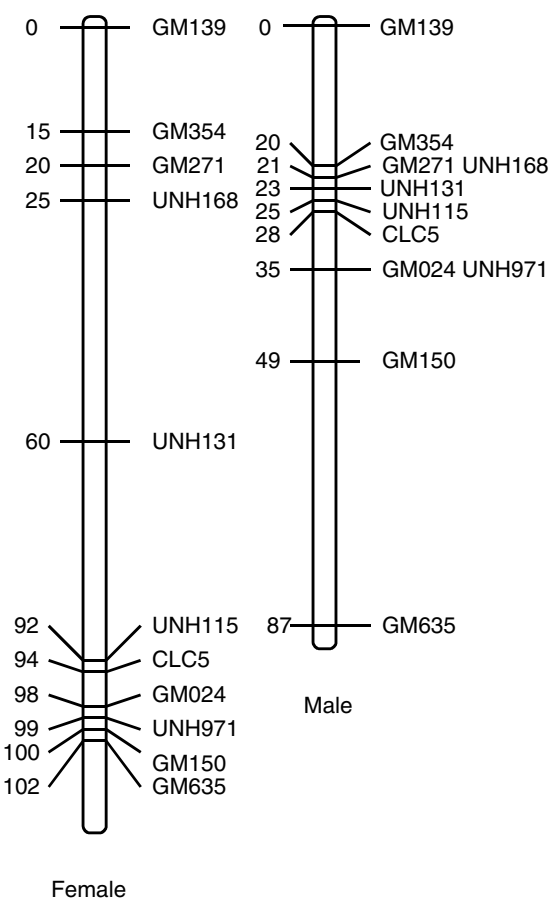

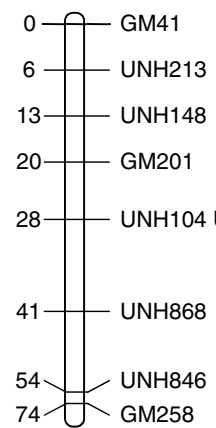

Female

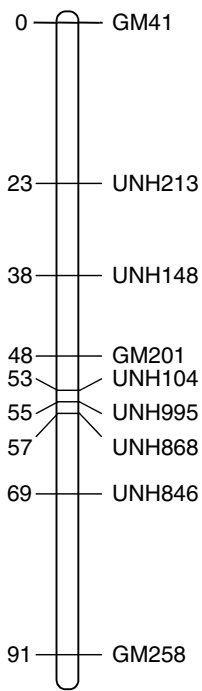

Male

Figure 2 Sex-specific linkage maps for LG3 and LG1 in Oreochromis aureus. 
additional genetic factors may be affecting determining the sex of these homozygotes. It is worth noting that we observed no effect of the putative WZ locus in three families of $O$. niloticus (Lee et al, 2003). This species may be fixed for a Z-like allele at the LG3 locus.

Sex-specific spatial variation in recombination rate has been observed in several fish species. Sakamoto et al (2000) observed much higher rates of recombination near the centromere in female rainbow trout. Conversely, male recombination rates were higher in the telomeric regions. We observed a similar sex-specific pattern of recombination, and predict that a centromere will be found near UNH131. In medaka, male recombination is suppressed in the region around the sex-determining gene and female recombination is suppressed in the telomeric regions (Kondo et al, 2001). Our results are also consistent with these patterns, suggesting they may be general for teleost fishes.

Our results begin to explain the variety of sex ratios that have been observed in pure and hybrid crosses of tilapia species. These DNA markers have immediate utility for tracking sex-linked haplotypes in breeding programs aimed at controlling the sex of fingerlings for commercial production. They also can be used in experiments aimed at quantifying the strength of different $\mathrm{W}$ - and Y-chromosome alleles from different individuals, strains and species. Marker-assisted selection could then be used to select genotypes that give a higher percentage of males for commercial production.

\section{Acknowledgements}

This work was supported by grants from the USDA (NRICGP \#98-03476) and the New Hampshire Agricultural Experiment Station (Hatch \#372). The development of the tilapia linkage map was greatly accelerated by collaboration with Woo-Jai Lee, Audun Slettan and Oystein Lie of Genomar ASA, Norway.

\section{References}

Abucay JS, Mair GC, Skibinski DOF, Beardmore JA (1999). Environmental sex determination: the effect of temperature and salinity on sex ratio in Oreochromis niloticus L. Aquaculture 173: 219-234.

Arkhipchuk VV (1995). Role of chromosomal and genome mutations in the evolution of bony fishes. Hydrobiol $J$ 31: 55-65.

Avtalion RR, Don J (1990). Sex-determining genes in tilapia: a model for genetic recombination emerging from sex ratio results of three generations of gynogenetic Oreochromis aureus. J Fish Biol 37: 167-173.

Baroiller JF, Chourrout D, Fostier A, Jalabert B (1995). Temperature and sex chromosomes governs sex ratios of the mouthbrooding cichlid fish Oreochromis niloticus. J Exp Zool 273: 216-223.

Baroiller JF, Guiguen Y, Fostier A (1999). Endocrine and environmental aspects of sex differentation in fish. Cell Mol Life Sci 55: 910-931.

Bull JJ (1983). Evolution of Sex Determining Mechanisms. Benjamin/Cummings: Menlo Park, CA.

Campos-Ramos R, Harvey SC, Masabanda JS, Carrasco LA Griffin DK, McAndrew BJ, Bromage NR, Penman DJ (2001). Identification of putative sex chromosomes in the blue tilapia, Oreochromis aureus, through synaptonemal complex and FISH analysis. Genetica 111: 143-153.
Desprez D, Mélard C (1998). Effect of ambient water temperature on sex determination in the blue tilapia Oreochromis aureus. Aquaculture 84: 41-48.

Desprez D, Mélard C, Hoareaua MC, Bellemènea Y, Bosca P, Baroiller JF (2003). Inheritance of sex in two ZZ pseudofemale lines of tilapia Oreochromis aureus. Aquaculture 218: 131-140.

Devlin RH, Nagahama Y (2002). Sex determination and sex differentiation in fish: an overview of genetic, physiological, and environmental influences. Aquaculture 208: 191-365.

Gilbert SF (1997). Developmental Biology. Sinauer Associates: Sunderland, MA.

Graves JAM (2002). The rise and fall of SRY. Trends Genet 18: 259-264.

Green P, Falls K, Crooks S (1990). Documentation for CRIMAP, Version 2.4. Washington University School of Medicine: St Louis, Missouri.

Guerrero III RD, Shelton WL (1974). An aceto-carmine squash method for sexing juvenile fishes. Prog Fish-Cult 36: 56.

Hammerman IS, Avtalion RR (1979). Sex determination in Sarotherodon (Tilapia). II. The sex ratio as a tool for the determination of genotype. A mathematical model of autosomal and gonosomal influence. Theor Appl Genet 55: 177-187.

Hickling CF (1960). The Malacca Tilapia hybrids. J Genet 57: $1-10$.

Hopkins KD (1979). Production of Monosex Tilapia Fry by Breeding Sex-reversed Fish. PhD Thesis, Auburn University, Auburn, Alabama, USA.

Hopkins KD, Shelton WL, Engle CR (1979). Estrogen sexreversal of Tilapia aurea. Aquaculture 18: 263-268.

Hulata G, Karplus I, Harpaz S (1995). Evaluation of some red tilapia strains for aquaculture: growth and colour segregation in hybrid progeny. Aquacult Res 26: 765-771.

Hussain MG, McAndrew BJ, Penman DJ, Sodsuk P (1994). Estimating gene centromere recombination frequencies in gynogenetic diploids of Oreochromis niloticus L. using allozymes, skin colour and a putative sex-determination locus (SDL-2). In: Beaumont AR (ed) Genetics and Evolution of Aquatic Organisms. Chapman and Hall: London, pp 502-509.

Just W, Baumstark A, Hameister H, Schreiner B, Reisert I, Hakhverdyan M, Vogel W (2002). The sex determination in Ellobius lutescens remains bizarre. Cytogenet Genome Res 96: 146-153.

Kocher TD, Thomas WK, Meyer A, Edwards SV, Pääbo S, Villablanca FX, Wilson AC (1989). Dynamics of mitochondrial DNA sequence evolution in animals. Proc Natl Acad Sci USA 86: 6196-6200.

Kocher TD, Lee WJ, Sobolewska H, Penman D, McAndrew B (1998). A genetic linkage map of a cichlid fish, the tilapia (Oreochromis niloticus). Genetics 148: 1225-1232.

Kondo M, Nagao E, Mitani H, Shima A (2001). Differences in recombination frequencies during female and male meioses of the sex chromosomes of the medaka, Oryzias latipes. Genet Res 78: 23-30.

Kondo M, Nanda I, Hornung U, Asakawa S, Shimizu N, Mitani H, Schmid M, Shima A, Schartl M (2003). Absence of the candidate male sex-determining gene $\operatorname{dmrt1b}(Y)$ of medaka from other fish species. Curr Biol 13: 416-420.

Kornfield IL (1984). Descriptive genetics of cichlid fishes. In: Turner BJ (ed) Evolutionary Genetics of Fishes. Plenum Publishing Corporation: New York, pp 519-616.

Kosswig C (1964). Polygenic sex determination. Experientia 20: 190-199.

Lahav E (1993). Use of sex-reversed females to produce all-male tilapia (Oreochromis aureus) fry. Isr J Aquacult - Bamidgeh 45: 131-136.

Lahav M, Lahav E (1990). The development of all-male tilapia hybrids in Nir-David. The Isr J Aquacult - Bamidgeh 42: 58-61.

Lee BY, Penman DJ, Kocher TD (2003). Identification of the sexdetermining region in tilapia (Oreochromis niloticus) using bulked segregant analysis. Anim Genet 34: 379-383. 
Lee B-Y, Lee W-J, Streelman JT, Carleton KL, Howe AE, Hulata G, Slettan A, Terai Y, Kocher TD (2004). A second generation genetic linkage map of tilapia (Oreochromis spp.). Genetics (submitted).

Li Y, Hill JA, Yue GH, Chen F, Orban L (2002). Extensive search does not identify genomic sex markers in Tetraodon nigroviridis. J Fish Biol 61: 1314-1317.

Mair GC, Abucay JS, Skibinski DOF, Abella TA, Beardmore JA (1997). Genetic manipulation of sex ratio for the large-scale production of all-male tilapia, Oreochromis niloticus. Can J Fish Aquat Sci 54: 396-404.

Mair GC, Penman DJ, Scott AG, Skibinski DOF, Beardmore JA (1987). Hormonal sex reversal and the mechanisms of sex determination in Oreochromis. In: Tiews K (ed) Proceedings of the World Symposium on Selection, Hybridization and Genetic Engineering in Aquaculture, Bordeaux, 27-30 May, 1986. Heenemann Verlagsgesellschaft: Berlin, Vol II, pp 289-300.

Mair GC, Scott AG, Penman DJ, Skibinski DOF, Beardmore JA (1991). Sex determination in the genus Oreochromis: 2. Sex reversal, hybridisation, gynogenesis and triploidy in $O$. aureus Steindachner. Theor Appl Genet 82: 153-160.

Majumdar KC, McAndrew BJ (1986). Relative DNA content of somatic nuclei and chromosomal studies in three genera: Tilapia, Sarotherodon and Oreochromis of the tribe Tilapiini. Genetica 68: 165-168.

Matsuda M, Nagahama Y, Shinomiya A, Sato T, Matsuda C, Kobayashi T, Morrey CE, Shibata N, Asakawa S, Shimizu N, Hori H, Hamaguchi S, Sakaizumi M (2002). DMY is a Yspecific DM-domain gene required for male development in the medaka fish. Nature 417: 559-563.

Mélard C (1995). Production of a high percentage of male offspring with $17 \alpha$-ethynylestradiol sex-reversed Oreochromis aureus. I. Estrogen sex-reversal and production of $F_{2}$ pseudofemales. Aquaculture 130: 25-34.

Michelmore RW, Paran I, Kesseli RV (1991). Identification of markers linked to disease-resistance genes by bulked segregant analysis: a rapid method to detect markers in specific genomic regions by using segregating populations. Pro Natl Acad Sci USA 88: 9828-9832.

Nanda I, Kondo M, Hornung U, Asakawa S, Winkler C, Shimizu A, Shan Z, Haaf T, Shimizu N, Shima A, Schmid M, Schartl M (2002). A duplicated copy of DMRT1 in the sexdetermining region of the $\mathrm{Y}$ chromosome of the medaka, Oryzias latipes. Proc Natl Acad Sci USA 99: 11778-11783.

Nanda I, Shan Z, Schartl M, Burt DW, Koehler M, Nothwang H, Grutzner F, Paton IR, Windsor D, Dunn I, Engel W, Staeheli P,
Mizuno S, Haaf T, Schmid M (1999). 300 million years of conserved synteny between chicken $\mathrm{Z}$ and human chromosome 9. Nat Genet 21: 258-259.

Penman DJ, Shah MS, Beardmore JA, Skibinski DOF (1987). Sex ratio of gynogenetic and triploid tilapia. In: Tiews K (ed) Proceedings of the World Symposium on Selection, Hybridization and Genetic Engineering in Aquaculture, Bordeaux, 27-30 May, 1986. Heenemann Verlagsgesellschaft: Berlin, Vol II, pp 267-276.

Phelps RP, Popma TJ (2000). Sex reversal of tilapia. In: CostaPierce BA and Rakocy JE (eds.) Tilapia Aquaculture in the Americas. The World Aquaculture Society: Baton Rouge, Louisiana, USA, Vol 2, pp 34-59.

Pruginin Y, Rothbard S, Wohlfarth G, Halevy A, Moav R, Hulata G (1975). All-male broods of Tilapia nilotica $\times$ T. aurea hybrids. Aquaculture 6: $11-21$.

Rosenstein S, Hulata G (1994). Sex reversal in the genus Oreochromis. II. Optimization of feminization protocol. Aquacult Fish Manage 25: 329-393.

Sakamoto T, Danzmann RG, Gharbi K, Howard P, Ozaki A, Khoo SK, Woram RA, Okamoto N, Ferguson MM, Holm LE, Guyomard R, Hoyheim B (2000). A microsatellite linkage map of rainbow trout (Oncorhynchus mykiss) characterized by large sex-specific differences in recombination rates. Genetics 155: 1331-1345.

Sarder MRI, Penman DJ, Myers JM, McAndrew BJ (1999). Production and propagation of fully inbred clonal lines in the Nile tilapia (Oreochromis niloticus L.). J Exp Zool 284: 675-685.

Shirak A, Palti Y, Cnaani A, Hulata G, Ron M, Avtalion RR (2002). Association between loci with deleterious alleles and distorted sex ratio in an inbred line of tilapia (Oreochromis aureus). J Hered 93: 270-276.

Sokal RR, Rohlf FJ (1981). Biometry, the Principles and Practice of Statistics in Biological Research. W. H. Freeman: San Francisco.

Trombka D, Avtalion RR (1993). Sex determination in tilapias a review. Isr J Aquacult - Bamidgeh 45: 26-27.

Wilkins AS (2002). The Evolution of Developmental Pathways. Sinauer Associates: Sunderland MA.

Wohlfarth GW (1994). The unexploited potential of tilapia hybrids in aquaculture. Aquacult Fish Manage 25: 781-788.

Wohlfarth GW, Hulata G (1983). Applied genetics of tilapias. ICLARM Stud Rev 6: 1-26.

Wohlfarth GW, Wedekind H (1991). The heredity of sex determination in tilapias. Aquaculture 92: 143-156.

Zarkower D (2001). Establishing sexual dimorphism: conservation amidst diversity? Nat Rev Genet 2: 175-185. 